\title{
Study on Level of Depression among Elderly Residing in an Old Age Home in Hyderabad, Telangana
}

\author{
Mrs Shweta Maktha ${ }^{1 *}$, Dr. M. Vijay $\operatorname{Kumar}^{2}$
}

\section{ABSTRACT}

Introduction: Depression is a major public health problem especially in geriatric population. With increasing trend of the concept of old age homes in India, the present study was designed to evaluate the depression among elderly in old age home and to recommend suggestive measures to prevent or reduce it. Material \& Methods: An institution based cross sectional study was done in an old age home of Hyderabad. 80 elderly clients were interviewed using a pre designed pre tested questionnaire. Assessment of depression was done by using Beck's Depression Inventory. Prior permission was taken from the Head of the old age home and informed consent was taken from the participants. Data entry was done using Microsoft Excel 2007 and analysis was done by using EPI INFO version 7. Results: Mean age of the respondents was $67.4 \pm 4.7$ years with majority in 66-70 years age group (61\%) and 55\% were males. Mean depression score was 21.64. Maximum of elderly clients 39 (48\%) had moderate depression and 23 (29\%) had mild mood disturbance. Prevalence of depression was significantly associated with increased age; in females; and with duration of stay in old age home. Conclusions: Prevalence of depression was high in the present study and the associated factors noticed were increased age; in females; and with duration of stay in old age home.

Keywords: Depression, Geriatric, Old Age Home, Hyderabad

Aging is a normal, universal and inevitable change which takes place even with the best of nutrition and health care. It is a time related change that occurs throughout life. Aging involves all aspects of the organism and largely characterized by a decline in functional efficiency and decreased capability to compensate and recover from stress. ${ }^{1}$ The life expectancy of human is increased in both developed and developing countries due to advancement and improvement of latest technology in medical field. Currently, the world wide life expectancy for males is 62.7 years and for females is 66 years, and India it is 65years. About $13 \%$ of the national population is over 65 years of age. ${ }^{2}$

\footnotetext{
${ }^{1}$ Psychology Counselor, Vijitha Counseling Centre, Nallakunta, Hyderabad

${ }^{2}$ Assistant Professor, Department of Community Medicine, Bhaskar Medical College, Moinabad, Rangareddy District, Telangana, India. use, distribution, and reproduction in any Medium, provided the original work is properly cited.
} 
Decreasing strength is the general physical change in the elderly. The sociologic Issues of ageing are concerned with work, retirement, social security, health care and the response to getting old age is related to lifelong habits, diet and exercise patterns. Old aged often becomes anxious if they live alone, lacking family support, poor income, accommodation and insecurity which may lead to depression. ${ }^{3}$

Although the elderly suffers from medical illness there is a greater contribution to mental health problems, especially the priority go to depression. Depression is pervasive and can diminish the spark of life. Depression is a mood disturbance characterized by exaggerated feelings to sadness, despair, lowered self esteem, loss of interest in former activities and pessimistic thoughts. Depressive disorders are the most common affective illness found in old age. Elderly suffering from acute or chronic illness showed higher prevalence of depression. The incidence of increased depression among the elderly is influenced by the variables of physical illness, functional disability and cognitive impairment. ${ }^{4}$

Unrecognized health problems are more common among elderly which include incontinence of urine, depression-dementia, visual-hearing impairment and locomotor disability. Depression is a common condition in older people affecting about 17-30 \% of community dwellers over the age of 65 years. Depression is one of the most common mental disorders affecting 340 million people in the world today. The World Health Organization (WHO) has predicted that by 2020, depression will be the second biggest health problem world-wide and leading cause of disability and death world-wide, second only to heart disease. ${ }^{5}$

With rapid urbanization and industrialization, the concept of old age homes will be at increasing trend even in countries like India. Hence the present study was designed to evaluate the depression among elderly in old age home and to recommend suggestive measures to prevent or reduce it.

\section{OBJECTIVES}

1) To enumerate the socio-demographic profile of the elderly residing in old age home

2) To study the level of depression among study participants

3) To assess various factors associated with depression

\section{MATERIAL \& METHODS}

Study Population: The population of the present study comprises the elderly residing in an old age home of Hyderabad.

Study design: Institution based cross sectional study

Study duration: 3 months from May to July 2014

Sample Size: Sample size of the present study consists of 80 elderly clients who are able to read, write and understand Telugu, Hindi or English. 


\section{Inclusion criteria:}

- Elderly people between 60-75 years of age, who can read, write and understand Telugu, Hindi or English.

\section{Exclusion criteria:}

- Elderly who are terminally ill and those who are not willing to participate in the study

\section{Study technique and Study tools:}

Using a pre-designed, pre tested questionnaire and assessment of depression by using Beck's Depression Inventory.

\section{Description of the tool:}

The tool used for gathering relevant data was a Standardized Beck's Depression Inventory (BDI). The final tool consists of two sections:

Section I: Demographic data

Section II: Standardized Beck’s Depression Inventory (BDI).

Beck's Depression Inventory is made up of 21 multiple choice self report items to be completed over ten to twenty minutes, each reflecting a negative emotional symptom. Each of these is rated with scores ranging from $0-3$ on the severity of the participants' experiences over the last week with the intention of emphasizing states over traits. ${ }^{6}$ Sum of the relevant 21 items for each scale constitutes the participants' scores for each of the emotions leading to Depression. Depression scores 1-10 indicates as mild ups and downs in mood disturbances, 11-20 as Mild mood disturbances, 21-30 as Moderate Depression, 31-40 as Severe Depression and above 40 as Extreme level of Depression. ${ }^{6}$ The tool was translated in Telugu and Hindi and retranslated back to English.

Ethical considerations: Prior permission was taken from the Head of the old age home after explaining the purpose of the study. Informed consent was taken from the participants and confidentiality was ensured.

Data analysis: Data entry was done using Microsoft Excel 2007 and analysis was done by using EPI INFO version 7. To find the association between variables, Univariate analysis using Chisquare test wherever necessary was done. The data obtained was analyzed in terms of the objectives of the study using descriptive and inferential statistics.

\section{RESULTS}

Socio demographic profile of the study population revealed that mean age of the respondents was $67.4 \pm 4.7$ years with majority in 66-70 years age group (61\%). Percentage of male respondents (55\%) was comparatively more than females. About three fourth of them belonged to Hindu religion and about $68 \%$ had two children.

With regards to admission to old age home, about three fourth (73\%) got voluntarily admitted to the old age home. Duration of stay in old age home was about one to two years in two thirds 
(67\%) of the respondents. About $43 \%$ of them were either partially or completely dependent on others for activities.

Table 1: Mean median, mode, standard deviation and range of depression scores of elderly

\begin{tabular}{|l|l|l|l|l|}
\hline & Mean & Median & Mode & $\begin{array}{l}\text { Standard } \\
\text { Deviation }\end{array}$ \\
\hline $\begin{array}{l}\text { Depression scores among } \\
\text { elderly residing in old age } \\
\text { home }\end{array}$ & $\mathbf{2 1 . 6 4}$ & 22 & 22.72 & 2.32 \\
\hline
\end{tabular}

In the present study, the mean depression score among elderly residing in old age home was 21.64 with median \& mode at 22 and 22.72 respectively. Standard deviation was 2.32.

Table 2: Frequency and percentage distribution of depression scores of elderly

\begin{tabular}{|l|l|l|l|}
\hline Level of depression & Score range & Frequency & Percentage (\%) \\
\hline Ups and downs are normal & $1-10$ & 07 & 09 \\
\hline Mild mood disturbance & $11-20$ & 23 & 29 \\
\hline Moderate depression & $21-30$ & 39 & 48 \\
\hline Severe depression & $31-40$ & 11 & 14 \\
\hline Extreme depression & Above 40 & 0 & 0 \\
\hline
\end{tabular}

Among the study population, maximum of elderly clients 39 (48\%) had moderate depression and 23 (29\%) had mild mood disturbance.

Prevalence of depression was significantly associated with increased age $(\chi 2=8.32, p=0.001)$; in females $(\chi 2=6.74, p=0.006)$; and with duration of stay in old age home $(\chi 2=6.84, p=0.003)$. Prevalence was more in inmates who stay for longer (>5years) duration (79\%) as compared to those staying for shorter (<3years) duration (61.5\%).

No significant association was found between depression and other socio demographic factors such as religion, marital status, number of children, performance of activity, admission to old age home ( $\mathrm{P}>0.05)$.

\section{DISCUSSION}

Present study which has been done with an objective to assess the prevalence of depression and its associated factors found that the mean depression score was 21.64. Maximum of elderly clients 39 (48\%) had moderate depression and 23 (29\%) had mild mood disturbance.

Prevalence of depression was significantly associated with increased age; in females; and with duration of stay in old age home. 
Prevalence was more in inmates who stay for longer (>5years) duration (79\%) as compared to those staying for shorter (<3years) duration (61.5\%). Rationale behind increased prevalence with increasing duration of stay could be due to feeling of isolation from outside world.

A similar kind of study done by Hom Nath Chalise in Nepal observed that the prevalence of depression was 57.8\%. Among them 46.7\% had mild, $8.9 \%$ had moderate and $2.2 \%$ had severe depression. A statistically significant correlation was found between feelings of depression and age, sex, previous family type, ethnicity, feeling of loneliness and instrumental activities of daily living. ${ }^{7}$

A study on depression in elderly inmates living in old age homes by Narkhede et al in Gujarat found that Maximum number of inmates (31.9\%) was in the age group of 65-69 years. Depression was observed more in not working inmates (65.8\%), as well as in those who stayed for shorter duration (64.1\%). Incidence of depression was less in inmates who were living with spouse $(57.7 \%)^{8}$

A comparative study on psychiatric morbidity among elderly residing in old age homes and in community by Nagaraj AKM et al in Mysore revealed that depression was present in 22\% of people in the community and $36 \%$ of old age home inmates. Psychosis was present in $26 \%$ of people in the community and $20 \%$ of old age home inmates. The psychiatric morbidity was high in elderly irrespective of the setting in which they live. ${ }^{9}$

A study on mental health problems among inhabitants of old age homes in Lucknow by Tiwari et al observed that depression (37.7\%) was found to be the most common mental health problem followed by anxiety disorders (13.3\%) and dementia (11.1\%). ${ }^{10}$

\section{CONCLUSIONS \& RECOMMENDATIONS}

Prevalence of depression was high in the present study and the associated factors noticed were increased age; in females; and with duration of stay in old age home.

Hence non-pharmacological interventions like Horticulture therapy, Meditation, Spiritual \& Philosophical sessions, involving in domestic activities like cooking may be employed to reduce the depression levels and to divert the mind. Regular counseling sessions should be done to those who suffer from moderate to severe depression. And regular visits to the old age home by the family members should be encouraged wherever it is feasible.

\section{REFERENCES}

1) Shah E (2002). Health of elderly people. In: Oxford textbook of public health $4^{\text {th }}$ Edition: 1713-36.

2) Park K. Park’s Text Book of Preventive and Social Medicine,22 ${ }^{\text {nd }}$ edition. Banarsidas Bhanot, Jabalpur. 2013; 549-551. 
3) Alexopolous. Stress, social Engagement and Psychological well being in Institutional setting. Evidence based on the minimum data set 2.0. Canadian Journal on aging. 19(supple.2) 2005. Pg no: 50-66.

4) Alexopolous. Stress, social Engagement and Psychological well being in Institutional setting. Evidence based on the minimum data set 2.0. Canadian Journal on aging. 19(supple.2) 2005. Pg no: 50-66.

5) World Health Organization (WHO). Global Health and Aging. Available from the following link: http://www.who.int/ageing/publications/global_health.pdf (last accessed on 21st June 2014)

6) Beck, A. T., Steer, R.A., \& Garbin, M.G. (1988) Psychometric properties of the Beck Depression Inventory: Twenty-five years of evaluation. Clinical Psychology Review, 8(1), 77-100.

7) Hom Nath Chalise. Depression among elderly living in Briddashram (old age home). Advances in Aging Research 3 (2014) 6-11.

8) Narkhede V, Likhar S, Rana A (2012). A study on depression in elderly inmates living in old age homes in Gujarat. Indian Journal of Research and Reports in Medical Sciences (IJRRMS). 2012; 2 (3): 21-23.

9) Nagaraj AKM, Mathew J, Nanjegowda RB, Majgi SM, Purushothama SM. Psychiatric Morbidity among Elderly people living in Old age homes and in the community: A Comparative study. Online J Health Allied Scs. 2011; 10 (4):5.

10) Tiwari SC, Pandey NM, Singh I. Mental health problems among inhabitants of old age homes: A preliminary study. Indian Journal of Psychiatry. 2012;54(2):144-148. doi:10.4103/0019-5545.99533. 